\title{
OSCURO OBOE DE BRUMA... MÉTRICA, RITMO E INTERPRETACIÓN
}

\author{
Por \\ José EnRIQue Martínez FernándeZ \\ Clara I. Martínez Cantón
}

\begin{abstract}
"Oscuro oboe de bruma" es el comienzo del primer canto de Noche más allá de la noche, de Antonio Colinas, cuya primera edición es de 1982. Es el comienzo también del "Post-scriptum" o poema final del mismo libro, si bien nuestro análisis se refiere sólo al canto primero. En un artículo anterior (Martínez Fernández, 2004) habíamos dado cuenta de las correcciones y ajustes métricos a que había procedido Antonio Colinas en las tres ediciones del poemario en 2004, como exento (Colinas, 2004), dentro de En la luz respirada (Colinas, 2004a) y en la sexta edición de la obra poética completa hasta el momento (Colinas, 2004b); tales correcciones fueron numerosas y afectaron a la mayoría de los cantos, y entre ellos, aunque mínimamente, también al primero, como veremos.

Conviene indicar que hablamos de "cantos" porque así ha llamado el propio autor a los poemas de que se compone el libro, tal vez por su trato continuado y fervoroso, como lector, traductor e intérprete, con los Canti leopardianos, o acaso para subrayar la unidad del poemario, que admite una lectura global, a la manera de los viejos poemas épicos, cuyas divisiones reciben el nombre de "cantos".

Noche más allá de la noche es, por lo tanto, un conjunto de treinta y cinco cantos numerados en romano y sin título. Cada canto consta de veintiocho versos alejandrinos; con los veinte
\end{abstract}


versos del "Post-scriptum" final tenemos un total de mil versos alejandrinos. La crítica ha insistido en tales datos, como es natural, adivinado en el número mil algún significado especial, de índole biográfica o de otro tipo.

El libro fue escrito entre junio de 1980 y julio de 1982 , en un momento crítico en la vida del poeta (problemas graves de salud, nacimiento del primer hijo, muerte de un amigo...) y en coincidencia con una serie de lecturas que Colinas siempre ha considerado decisivas en su vida y en su poesía a partir de Noche más allá de la noche: taoísmo, mística universal, neoplatonismo renacentista, romanticismo centroeuropeo y pensadores del siglo xx como C. G. Jung, Mircea Eliade o María Zambrano. Acaso tales circunstancias vitales, de honda y permanente huella en su obra posterior, sean las que motiven el aprecio que Antonio Colinas ha sentido por Noche más allá de la noche y que ha vuelto a explicitar en nota final a la edición exenta del poemario en 2004, en la que indica los motivos de su predilección, algunos de tipo biográfico; entre ellos nos interesan tres principalmente, puesto que afectan a la interpretación del poemario: la inflexión que se da de la emoción al pensamiento, el intento de sintetizar poéticamente algunos momentos claves del "espíritu" universal (los orígenes, Grecia, Roma, Renacimiento, etc.) y las varias lecturas posibles y complementarias del libro, como un solo poema o como treinta y seis composiciones autónomas (Colinas, 2004: 45), además de las que la crítica ha sumado (lectura mística o mistérica, por ejemplo). Parece indudable que Antonio Colinas concibió el poemario de forma global y circular, por cuanto el "Post-scriptum" supuso, con sus veinte alejandrinos, la suma emblemática de mil versos, además de representar la vuelta circular al canto I, cuyos dos versos iniciales lo son también del "Post-scritum", dentro de cual funcionan como estribillo de aparición irregular. De esta manera, Noche más allá de la noche se nos presenta como una melodía, funcionando el poema final a modo de ritornelo y vuelta al inicio melódico. En cualquier caso, nos centraremos únicamente en el canto $\mathrm{I}$. 


\section{Métrica y ritmo}

Como ya hemos indicado, el canto I, al igual que los otros treinta y cuatro que siguen, se compone de veintiocho versos alejandrinos, un metro en el que, junto al endecasílabo, Colinas se ha sentido especialmente cómodo. El alejandrino lo había empleado Colinas ya en su primer libro, Junto al lago, escrito en 1967, pero conservado inédito como libro hasta la sexta edición de El río de sombra (Colinas, 2004b), y es el verso único de su segundo libro, Poemas de la tierra y de la sangre (1969), todo él en dicho metro, como después Noche más allá de la noche. Sin embargo, la crítica, más atenta al ejercicio hermenéutico que al análisis métrico, apenas se ha detenido en el uso concreto del alejandrino por parte del poeta, salvo excepciones como la de Huerta Calvo (1997: 214-218), con su análisis minucioso y preciso del canto $\mathrm{X}$.

El canto I es el siguiente:

Oscuro oboe de bruma, cómo sepulta el mar tu solemne sonido que despierta a los muertos.

Aquí, en esta ladera que cubre el olivar sangre y labio repiten musicales conciertos.

La ladera y sus soles que maduran los vinos

la tensión del azul volcado de los cielos, armonía y vacío en espacios divinos, horror al más allá tras las costas de Delos. Perdición, extravío de las horas oscuras del corazón que sueña, en la luz, otros mundos, mientras la boca va desgranando las puras notas de arte mortal en los hondos, inmundos socavones del mal. Pues, ¿por qué se da guerra junto a amor y por qué la voz de la ebriedad y el dolor infinito van girando en la tierra?

Un año más se funden misterio y soledad. Y, sin embargo, tú, estrella de la tarde, ves llegar el final, los bordes del ocaso. ¿Qué secretos oculta este cosmos que arde sobre la muerte y qué nos reserva el acaso? Mas, en el hondo instante, la música revela la inmensidad del orbe, la dimensión del ser. 
Un aroma de azahar la angustia nos desvela.

Horror y sed de dioses tras otro atardecer.

Oscuro oboe de bruma, entreabre las venas

del mundo en esta paz y arrasa la Historia.

Vida y muerte se acercan como olas serenas

al corazón que ahuyenta, soñando, la memoria ${ }^{1}$.

«Hago un tipo de alejandrino en el que la cesura esta muy marcada; en realidad son dos versos de siete sílabas» (Colinas, 1994: 68). El alejandrino se compone, como se sabe, de dos hemistiquios de siete sílabas cada uno, de forma que la pausa entre uno y otro funciona como la pausa final de verso. Antonio Colinas delimita los dos hemistiquios heptasilábicos con pausa o cesura intensa entre ellos. Las correcciones introducidas para las ediciones de Noche más allá de la noche en 2004 suponen además que cada hemistiquio tenga, como principio general, siete sílabas cabales, con las correspondientes sinalefas como fenómeno generalizado, lo que no sucedía en ediciones anteriores. La pausa entre los dos hemistiquios supone que cada uno de ellos lleve acento, invariablemente, sobre la sexta sílaba, es decir, sobre las sílabas sexta y decimotercera del alejandrino. Supone también la equivalencia de final agudo, grave y esdrújulo del primer hemistiquio - al igual que ocurre con la pausa final de verso y de segundo hemistiquio-, lo que podemos ejemplificar en numerosos casos de terminación en sílaba aguda: versos 6 ("la tensión del azul"), 8 ("horror al más allá"), 11, 12, 13, 14, $17,18,20,23$ y 26 . Habría que añadir que la sinalefa se practica en todos los casos, con dos excepciones:

a) En el verso 26 el segundo hemistiquio necesita, para ser heptasilábico, hacer hiato entre "y" y "arrasa" o entre "la" e "Historia"; por ejemplo:

del-mun-doen-es-ta-paz / y-arra-sa-laHis-to-ria.

${ }^{1}$ Transcribo el texto de En la luz respirada, que no presenta variantes léxicas con especto a las otras dos ediciones de 2004; anotamos que en éstas los versos 1 y 25 llevan dos puntos en vez de coma: "Oscuro oboe de bruma: cómo sepulta el mar». En las tres ediciones de dicho año, la forma sobre del verso 20 sustituye a la preposición en que aparecía en ediciones anteriores. 
b) El verso 27 realiza un hiato entre "como" y "olas" en el segundo hemistiquio:

\section{Vi-day-muer-te-sea-cer-can / co-mo-o-las- se-re-nas}

Es extraño que en las ediciones de Noche más allá de la noche en 2004 no procediera Colinas a la eliminación de estos hiatos, tal como hizo en el verso 20, que en su versión anterior («en la muerte y qué nos reserva el acaso?») necesitaba un hiato entre " $y$ " y "qué" para que el primer hemistiquio fuera un heptasílabo; y como hizo en la mayoría de los casos con las correcciones introducidas ${ }^{2}$.

El hiato, como indicábamos, es obligado entre dos hemistiquios cuando el primero termina en vocal y el segundo empieza por vocal también. Es el caso de los vv. 7, 10, 17, 19 y 25:

armonía y vacío / en espacios divinos (v. 7)

del corazón que sueña, / en la luz, otros mundos (v. 10)

Y, sin embargo, tú, / estrella de la tarde (v. 17)

¿Qué secretos oculta / este cosmos que arde (v. 19)

Oscuro oboe de bruma, / entreabre las venas(v. 25)

En este último verso, así como en el primero del canto, es importante señalar la sinéresis en "oboe" (o-boe), fenómeno que afecta también al verso 23, "azahar" (a-zahar).

Aspectos métricos como los hasta aquí señalados no singularizan este canto I de los restantes de Noche más allá de la noche. La rima, sin embargo, sí sustancia algunas diferencias. En efecto, sólo los cantos I, VI, XI, XIV, XV, XVI y XXXIII van rimados. Los demás, incluido el "Post-scriptum" se organizan métricamente como alejandrinos blancos. El canto I, como los otros seis cantos con rima, se desarrolla en siete serventesios,

\footnotetext{
${ }^{2}$ Valgan dos ejemplos significativos de un canto tomado al azar, el XXI:

v. 10: de aves casi quietas. / No despierto, retorno ( $1^{\mathrm{a}}$ ed.): hiato entre "de" y "aves".

de pájaros inmóviles. / No despierto, retorno (2004)

v. 19: En mis venas se va/ desangrando un dios ( $1^{\mathrm{a}}$ ed.): hiato entre "desangrando" y "un".

En mis venas se va / desangrando aquel dios (2004).
} 
con rima consonante, por lo tanto. No conozco declaraciones del poeta, Antonio Colinas, en relación con la rima, ni es fácil interpretar el porqué de los siete cantos rimados, si no es por el deseo de introducir alguna variedad rítmica y eufónica en el conjunto.

La rima, como marca fónica a final de verso, contribuye a delimitar cada uno de ellos; sin embargo, dada la longitud de los alejandrinos y el carácter alterno de la rima, tal marca se diluye en buena parte. En el caso que nos ocupa, el canto I, tres de las estrofas contienen rimas agudas. Son muy significativas, por su aproximación semántica, rimas como "mar-olivar" -alusivas al espacio fundacional en el que brota la poesía, como veremos-, "ebriedad-soledad" -que cifran momentos de exaltación que sólo es posible experimentar en compañía de uno mismo-, "revela-desvela", como efectos del arte, de la música, y "memoria-Historia", pareja demasiado previsible, dada su frecuencia en nuestra tradición poética.

Cabe hablar de rimas internas, probablemente ocasionales, aunque muy significativas. En cualquier caso, inciden sobre el efecto acústico del poema, porque el conjunto de esas rimas interiores está muy trabado fónicamente, dado que todas ellas, nada menos que siete, cuando no consuenan (lo que sí hacen varios términos), al menos asuenan entre sí. Se trata de las siguientes terminaciones, siempre en sílaba final del primer hemistiquio, omitiendo otras coincidencias fónicas de menos interés ${ }^{3}$ :

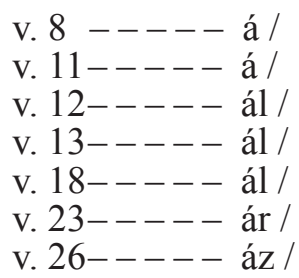

Como puede observarse, el conjunto rima en asonancia (á), pero dentro del mismo, se perciben algunas consonancias

${ }_{3}^{3}$ Por ejemplo, esta serie que atraviesa el poema: tensión (v. 6), horror (v. 8), perdición (v. 9), corazón (v. 10), amor, voz (v. 14), dolor (v. 15), horror (v. 24), corazón (v. 28). 
(tres terminaciones en -ál). Estas rimas internas presentan dos características que las hace especialmente relevantes:

a) Todas ellas marcan, como ya adelantamos, el final del primer hemistiquio en sus respectivos versos:

$\begin{array}{ll}\text { v. } 8 & \text { horror al más allá / } \\ \text { v.11 } & \text { mientras la boca va / } \\ \text { v.12 } & \text { notas de arte mortal / } \\ \text { v.13 } & \text { socavones del mal / } \\ \text { v.18 } & \text { ves llegar el final / } \\ \text { v. } 23 & \text { Un aroma de azahar / } \\ \text { v. } 26 & \text { del mundo en esta paz / }\end{array}$

Estas rimas no delimitan el verso en cuanto tal, pero entendido el alejandrino como un compuesto de dos hemistiquios de siete sílabas cada uno, parece indudable que estas rimas interiores, y seguramente accidentales, se mueven «entre el ritmo y la eufonía», como tituló un artículo sobre el asunto Domínguez Caparrós (1997).

b) Estas rimas interiores asuenan, como conjunto, con las rimas agudas del primer serventesio (mar-olivar) y del cuarto (ebriedad-soledad), proporcionando al poema notable trabazón fónica, aunque, a la vez, debilitan la percepción neta del verso alejandrino en cuanto tal, pues «el uso de la rima interna, sobre todo si se coloca de forma simétrica, pone en peligro la unidad del verso y de la estrofa» (Domínguez Caparrós, 1999: 334), y más si tales rimas, a final de hemistiquio, aparecen en versos contiguos, caso de los versos 11 (va), 12 (mortal) y 13 (mal). Ir más allá en la interpretación, buscando correspondencias semánticas entre las palabras rimadas (por ejemplo entre "mortal", "mal" y "final") puede responder más a impresiones del lector que a un análisis objetivo.

El ritmo acentual, atendiendo a los dos heptasílabos que forman cada uno de los versos, no es regular a lo largo de poema, que combina los ritmos yámbico (acentos en sílabas pares), anapéstico (acentos en tercera y sexta sílabas) y mixto (acentos en primera, cuarta y sexta sílabas), tal como los define Domínguez Caparrós (1993: 145). Ritmo yámbico puro tienen, por ejemplo, 
los primeros hemistiquios de los vv. 1 y 8 ; anapéstico, los dos hemistiquios de los vv. 2, 5, 7, etc.; y mixto, el segundo hemistiquio del primer verso, entre otros muchos. Domina el ritmo anapéstico sobre los demás. Nos interesa aquí la expresividad del ritmo, muy relevante en relación con la naturaleza y disposición de las vocales, las tónicas sobre todo, en determinados versos, de los que analizaremos sólo dos casos concretos, entre otros dignos de tener en cuenta, dada la fácil caída en la impresión subjetiva que presentan consideraciones de este tipo:

a) Verso 1:

Oscuro oboe de bruma, cómo sepulta el mar.

El ritmo yámbico puro del primer hemistiquio refuerza su intensidad con la disposición de las vocales:

o ... ú ... o ... óe ... e ... ú ... a

Las vocales graves se suceden como golpes de gong, más que como sonidos de oboe, hasta la abierta final, con acentos sobre las graves (ú ... ó ... ú), que en el imaginario del hablante español connotan, según el contexto, miedo, lobreguez, etc., intensificando el sentido de la brillante sinestesia inicial, que nos encamina desde le principio al ámbito de lo misterioso; sucede lo mismo con la sucesión de tónicas graves en el segundo hemistiquio, que acaban desembocando - tal nos parece- en la vocal abierta de "mar":

$$
\text { ó... o ... e ... ú ...ae ... á. }
$$

A esta inicial zambullida en lo misterioso sucede un segundo verso cuyo ritmo anapéstico contribuye a realzar la "solemnidad" a la que alude, ofreciendo, además, un claro contraste con las vocales tónicas del verso anterior, pues las del verso segundo son todas agudas y casi monocromáticas (é... í ... é ... é):

tu solemne sonido que despierta a los muertos 
b) Verso 22:

La inmensidad del orbe, la dimensión del ser

El verso alude a magnitudes físicas (primer hemistiquio) o espirituales (segundo hemistiquio) de tal alcance que sólo la música, considerado arte absoluto por el poeta, puede revelar. Se trata de dos hemistiquios cuyo paralelismo rítmico (acentos en cuarta y sexta sílabas) y sintáctico refuerza su proximidad conceptual:

la inmensidad del orbe

la dimensión del ser

Pero, además, las semejanzas fónicas evidentes (vocálicas y consonánticas) se matizan con determinados contrastes (vocales tónicas diferentes: á ... o / ó ... é) que marcan la gradación conceptual de uno a otro hemistiquio.

Conviene añadir que el impulso rítmico del verso, dilatando la aparición del primer acento hasta la cuarta sílaba en cada uno de los hemistiquios contribuye a experimentar la sensación de lo inconmensurable expresado por el verso.

En el canto I de Noche más allá de la noche domina la esticomitia. Es verdad que abundan los encabalgamientos internos entre los hemistiquios de un mismo alejandrino (versos 2, 3, 5, 6 , etc.). No creemos que los valores estilísticos de este tipo de encabalgamiento medial equivalgan a los del encabalgamiento versal. El dislocamiento entre ritmo métrico y ritmo de frase que supone el encabalgamiento, para darse tiene que ser claramente perceptible, y nos tememos que tal percepción queda muy aminorada auditiva y visualmente en el caso del encabalgamiento medial. El verdadero desajuste o "deslazamiento", como lo llamaba Herrera, entre metro y sintaxis se produce con el encabalgamiento versal, éste sí claramente perceptible.

Los encabalgamientos versales del canto I se dan entre los versos 9-10 (las horas oscuras / del corazón), 11-12 (las puras / notas), 12-13 (inmundos / socavones) y 25-26 (las venas / del mundo). Se trata, en los cuatro casos, de encabalgamientos 
sintagmáticos. Los tres primeros afectan al mismo serventesio y vienen motivados en buena parte por la rima; la característica común a los tres es su función de relevar en final de verso el elemento de menor entidad semántica dentro del sintagma, el adjetivo (oscuras, puras, inmundos); como característica diferencial, el tercero de los encabalgamientos acaba abruptamente en el verso encabalgado (...rompiendo en los hondos, inmundos / socavones del mal), rompiendo el ritmo suave y modulado de los cuatro versos anteriores y, a la vez, intensificando la impresión de caída o hundimiento que sugiere la palabra "socavón".

\section{Interpretación}

A la hora de proceder a la interpretación del canto I de Noche más allá de la noche hay que empezar diciendo que el poemario, se vea como un todo o como una serie de composiciones distintas, es de una gran complejidad. Parece indudable que en la sucesión de los cantos existe un orden interior que se manifiesta en el carácter circular del poemario, cuyo canto último o "Postscriptum" supone, como indicamos páginas atrás y ahora recordamos, un retorno al canto primero, al reiterar como estribillo los dos versos iniciales de este canto I, en el que centraremos nuestra indagación en busca de su sentido, como si fuera una composición independiente de los demás.

El "oscuro oboe de bruma" representa por sinécdoque a la música. La imagen sinestésica no era nueva en la poesía de Colinas; había aparecido en ella tempranamente, en concreto en el V de "Los cantos de ónice", de Truenos y flautas en un templo (1972): "Quise con vuestros huesos hacer flautas, oscuros oboes de bruma"; después reaparecerá parcialmente en "Penumbra de la piedra", de Astrolabio (1979): «No serán dos las músicas que suenan / sino una sola, oboe entre la bruma». Hallada la imagen, probablemente el poeta se sintió sugestionado por su sonora gravedad, a la que contribuye poderosamente la armonía vocálica, como ya vimos. El "oscuro oboe de bruma" -la música-tiene en este poema intensas virtudes armonizadoras. De hecho, los dos primeros versos aluden a ellas, pues el sonido del oboe, elevado a son órfico, es tan poderoso que logra penetrar en el vacío del mar y despertar su pasado. 
En nuestro breve acercamiento hermenéutico al poema tendremos en cuenta los motivos que, entrelazados, se suceden en el mismo: el espacio fundacional, las dualidades contrarias y la anhelada fusión entre ellas.

1. El espacio fundacional es un motivo recurrente tanto en los ensayos como en la poesía de Antonio Colinas. Toma el concepto del libro Lo sagrado y lo profano, de Mircea Eliade, y alude con él al espacio «en el que el hombre hace sus preguntas. Son preguntas de siempre [...], consustanciales al vivir» (Colinas, 2001: 117). En ese espacio vacío, entre la tierra y los astros, el hombre intuye la presencia de la Divinidad y expresa sus inquietudes existenciales con interrogaciones como las que aparecen en los versos 13-15 («ipor qué se da guerra junto a amor...?») y 19-20 («¿Qué secretos oculta este cosmos...?»), con referencia a la presencia de perturbadoras dualidades opuestas en el primer caso y sobre el misterio cósmico y el destino humano en el segundo. Es el desasosiego existencial el que origina tales interrogantes.

Este canto I nos sitúa en un espacio fundacional que ha sugestionado al poeta: la «ladera que cubre el olivar» (v. 3), «"la ladera y sus soles que maduran los vinos» (v. 5). Ha escrito el poeta:

Ese espacio fundacional viene representado por una ladera escabrosa que desciende desde los montes hasta el mar. Sí, el paisaje es, si el lector así lo ve, ese paisaje tópico y bello que encontramos en algunas riberas del Mediterráneo. En este primer canto, sólo un nombre -Delos- proporciona la pista de la sabiduría en la que se fundamenta la reflexión del poeta: la griega (Colinas, 2001: 117).

Aludía Antonio Colinas, en concreto, a la ladera del monte Helicón, en la que el pastor-poeta de la Teogonía de Hesíodo se hacía sus preguntas (Colinas, 2001: 117), por más que la imagen se repita -se universalice- en otras laderas del Mediterráneo. Y junto a la ladera, el mar. El mismo Colinas aproximó los espacios de la ladera escabrosa del monte y el mar en un hermoso ensayo titulado "Paisaje mediterráneo y teoría lírica" (Colinas, 1989), donde indaga en ese espacio primordial y arquetípico en el que nace el canto, la poesía primera u originaria, los "musicales 
conciertos" a los que se refiere el poema. El canto brotaba en ese espacio vacío ("armonía y vacío") en el que el hombre vivía religado a la Divinidad ("espacios divinos"). Ladera y mar componían ese espacio conocido en el que el hombre, entre dudas e incertidumbres cantaba. Más allá, el "horror" a lo desconocido, al "Mare Magnum", con la isla de Delos - hoy deshabitada, pero con restos arqueológicos seculares- como símbolo de los límites, otro motivo lleno de simbolismo en la poesía de Colinas. Pero en ese espacio primero, fundacional, originario, algo perturba al hombre (al primitivo y al contemporáneo): las temidas dualidades.

2. El acoso de los contrarios es lo que provoca las interrogaciones del hombre. «El corazón que sueña, en la luz, otros mundos» (v. 10) es el polo ideal opuesto a «las puras / notas de arte mortal en los hondos, inmundos / socavones del mal» (vv. 11-13). Los versos 9-15 expresan estas dualidades contrarias: «guerra junto a amor»", «la voz de la ebriedad y el dolor infinito».

En la obra toda de Colinas las dualidades contrarias que perturban el existir del hombre configuran una de las recurrencias temáticas de mayor calado, puesto que explican, en buena parte, la concepción que el poeta tiene del mundo y de la vida. Habla Colinas de «la inevitable dualidad del ser» y nombra como «actitudes contrarias» la incertidumbre y la ociosidad, la reflexión y el vacío mental, duda y certeza, amargura y placer, oscuridad y luz, el ser y el no ser... (Colinas, 1991: 34). Muchos de los símbolos colinianos expresan dualidades consustanciales al mundo y al hombre: el bosque (muerte y renacimiento), la piedra (duración y ruinas), la isla (paraíso y cárcel), etc. Ante la imposibilidad de eliminar los contrarios, el poeta buscará la tensión armónica entre ellos y acaso la anhelada fusión, la unidad como ideal, acaso sólo fruto del sueño, del ideal: «Hoy, como ayer y

4 "Maremagnum" era el título que llevaba el canto I en Poesía, 1967-1980 (Madrid: Visor, 1982), donde Colinas dio un adelanto de diez composiciones que iban a formar parte del posterior Noche más allá de la noche, sin numerar, pero con título. Partiendo del significado de la palabra, puede interpretarse como «la confusión de realidades antagónicas que la vida misma ofrece al hombre» (Alonso Gutiérrez, 1990: 94), pero el título alude también, sin duda, al significado etimológico de "mar grande" y al propio Mediterráneo, al que los romanos llamaron, además de "Mare Nostrum", "Mare Magnum". 
como siempre, fundir armoniosamente los extremos es el gran don que perseguimos» (Colinas, 1991: 22).

3. La inquietud existencial se ha manifestado en las interrogaciones a las que nos hemos referido, una sobre los contrarios inexplicables (guerra-amor, ebriedad-dolor) y otra sobre el misterio del cosmos («¿Qué secretos oculta este cosmos...?») y el destino del hombre («...¿qué nos reserva el acaso?»). ¿Cómo salir del laberinto de los opuestos? Colinas ha escrito que a través de la ensoñación. En ese espacio primordial, «el poeta contempla y, sin más, busca la adormidera de la ensoñación para huir de la memoria, es decir, del dolor» (Colinas, 2001: 117). Del dolor y de la Historia, de los rastros históricos, que perturban la actitud contemplativa en la que, finalmente, los contrarios pueden convivir armónicamente. El símbolo de la fusión es la música, arte absoluto, cósmico y universal, y símbolo supremo de la armonía y la unidad para Colinas, dentro de un pensamiento vinculado a la tradición órfico-pitagórica. Una única cita: «Una música inspirada quiebra - ¿momentáneamente?- la incertidumbre que produce toda dualidad. La música es el más fiel reflejo a nuestro alcance de la anhelada Unidad» (Colinas, 1991: 33). La música posee intensas virtualidades para Colinas, entre ellas llevar al hombre a una ebriedad emocional superadora de las contingencias temporales de la vida y de la historia. En ese «hondo instante» de ebriedad, acaso sólo momentáneo, como el poeta teme, la música, el oscuro oboe que la representa, «revela / la inmensidad del orbe, / la dimensión del ser», que José Olivio Jiménez (1984: 38 ) ha interpretado como integración suprema del hombre y el mundo: otra vez la unidad, por lo tanto.

Ebriedad, paz final en la que, olvidados los accidentes de la Historia, los contrarios mayores, «vida y muerte se acercan como olas serenas», en unidad -no sabemos si momentánea también-, al menos mientras persista «la adormidera de la ensoñación para huir de la memoria, es decir, del dolor» (Colinas, 2001: 117).

La música, símbolo y realidad, es la manifestación más alta de la armonía cósmica universal en la que se funden los contrarios. También la poesía es una manifestación concreta del ritmo del mundo. No es extraño que Noche más allá de la noche se haya entendido, en la línea pitagórica recogida por Fray Luis de León, 
como «la música callada con que el alma responde acordadamente a la música también silenciosa del universo, los astros, el cosmos» (Jiménez, 1984: 38). El análisis métrico del canto I nos ha revelado una orquestación verbal que, como la música embriagadora, contribuye a paliar el desasosiego causado por las interrogaciones sin respuesta sobre el misterio cosmológico y el destino humano.

\section{Referencias bibliográficas}

Alonso Gutiérrez, Luis Miguel (1990): El corazón desmemoriado. Claves poéticas de Antonio Colinas. León: Diputación provincial.

Colinas, Antonio (1989): "Paisaje mediterráneo y teoría lírica", en El sentido primero de la palabra poética. Madrid / México: FCE, 33-41.

-(1991): Tratado de armonía. Barcelona: Tusquets.

-(1994): "Coloquio con Antonio Colinas", en Trabanco, Nieves (ed.): Diálogos sobre poesía española. Frankfurt / Madrid: Vervuet Verlag / Iberoamericana, 47-77.

-(2001): "Sobre Noche más allá de la noche", en Del pensamiento inspirado II. Junta de Castilla y León, 116-121.

-(2004): Noche más allá de la noche. Valladolid: Fundación Jorge Guillén.

-(2004a): En la luz respirada. Sepulcro en Tarquinia, Noche más allá de la noche, Libro de la mansedumbre. Madrid: Cátedra (ed. de José EnRIQuE MARTínEZ FERNÁNDEZ).

-(2004b): El río de sombra. Treinta y cinco años de poesía, 1967-2002. Madrid: Visor Libros.

Domínguez CAPARrós, José (1993): Métrica española. Madrid: Síntesis. -(1997): La rima: entre el ritmo y la eufonía. Valencia: Ediciones Episteme, col. Eutopías, vol. 175 (incluido en Estudios de métrica. Madrid: UNED, 1999, 149-169).

-(1999): Diccionario de métrica española. Madrid: Alianza Editorial.

Huerta Calvo, Javier (1997): "Comentario de un poema de Antonio Colinas (Noche más allá de la noche, canto X)", en Colinas, Antonio et alii (1997): El viaje hacia el centro (La poesía de Antonio Colinas). Madrid: Calambur, 211-228.

Jiménez, José Olivio (1984): “La poesía de Antonio Colinas", prólogo a Colinas, Antonio: Poesía 1967-1981. Madrid: Visor Libros, 9-49.

Martínez Fernández, José EnRiQue (2004): “Armonía y ritmo en Antonio Colinas: Ajustes métricos en Noche más allá de la noche", en Rhythmica, año II, $\mathrm{n}^{\circ}$ 2, Sevilla, 137-158. 